Check for updates

Cite this: RSC Adv., 2019, 9, 1956

Received 23rd October 2018

Accepted 8th January 2019

DOI: $10.1039 / \mathrm{c} 8 \mathrm{ra0} 0895 \mathrm{~d}$

rsc.li/rsc-advances

\section{Conformational transition of a non-associative fluorinated amphiphile in aqueous solution. II. Conformational transition vs. supramolecular assembly $\dagger$}

\begin{abstract}
Marc B. Taraban, (DD a Daniel J. Deredge, ${ }^{a}$ Margaret E. Smith, ${ }^{a}$ Katharine T. Briggs, ${ }^{a}$ Yue Feng, $\$^{a}$ Yu Li, ${ }^{b}$ Zhong-Xing Jiang, (D) ${ }^{b}$ Patrick L. Wintrode ${ }^{\star a}$ and Yihua Bruce Yu ${ }^{\star a}$

Unlike many known amphiphiles, the fluorinated amphiphilic dendrimer studied in this work demonstrated a concentration-dependent conformational transition rather than micellization or assembly. Hydrophobic and hydrophilic interactions with water were suggested as the most probable driving force of this transition. This assumption was consistent with the observed ${ }^{19} \mathrm{~F}$ chemical shift changes of the dendrimer compared to a known micelle-forming fluorinated amphiphile. Since water is an important factor in the process, trends of the concentration-dependent changes in water proton transverse relaxation rate served as an indicator of structural changes and/or supramolecular assembly. The conformational transition process was also confirmed by ion-mobility mass-spectrometry. We suggested that structural features, namely, steric hindrances, prevented the micellization/assembly of the dendrimer of this study. This conclusion might inform the approach to develop novel unconventional amphiphiles.
\end{abstract}

\section{Introduction}

Amphiphiles are organic molecules formed by a hydrophobic moiety and a hydrophilic moiety. Many natural (e.g., phospholipids) and synthetic (e.g., detergents) amphiphiles are known, which play a variety of important roles in biology, medicine, engineering, and daily life. Therefore, the design of new amphiphiles with novel properties is of much interest to diverse areas of human activities. Structure and properties of amphiphiles in solution often depend on their concentration-a result of their amphiphilicity and a source of their function. The most commonly known concentration-dependent behavior of amphiphiles is, perhaps, micellization, where the individual amphiphilic molecules assemble together to form an aggregated supramolecular entity as the concentration increases. When the solvent is water, such an assembly is driven by the need to minimize the interaction between water and the hydrophobic moiety of the amphiphile. As a result, hydrophobic

\footnotetext{
${ }^{a}$ Department of Pharmaceutical Sciences, School of Pharmacy, University of Maryland, 20 Penn Street, Baltimore, MD 21201, USA. E-mail: byu@rx.umaryland.edu; pwintrod@rx.umaryland.edu; Fax: +1 410-706-5017; Tel: +1 410-706-7514; +1 410706-6639

${ }^{b}$ School of Pharmaceutical Sciences, Wuhan University, Wuhan, Hubei 430071, China $\dagger$ Electronic supplementary information (ESI) available: Water proton transverse relaxation rates $v s$. concentration of fluorinated dendrimer, sodium octanoate and $\alpha$-cyclodextrin; mass-spectra of fluorinated dendrimer at different concentrations. See DOI: 10.1039/c8ra08795d

\$ Current address: Pfizer, Inc., Groton, CT 06340, USA.
}

groups of an amphiphile are buried inside the supramolecular assembly (micelles), and thereby, sequestered from water, while the hydrophilic groups are exposed to interact with the surrounding water molecules. The concentration where half of the amphiphile population exists in the aggregated state (micelles) is called the critical micelle concentration (CMC). ${ }^{1}$

Not all amphiphiles form micelles. In certain cases, the assembly of amphiphile monomers might be sterically hindered. For example, cyclodextrins (CDs), a class of cyclic oligosaccharides, have a hydrophilic outer surface and a hydrophobic inner cavity. The amphiphilic nature of CDs is exploited in drug formulation for solubilization of otherwise insoluble molecules via the formation of inclusion complexes. ${ }^{2}$ The exterior of CDs provides solubility in water while their hydrophobic cavity accommodates hydrophobic drug molecules. ${ }^{3}$ Their amphiphilicity notwithstanding, the structure of CDs is incompatible with micellization and unmodified CDs do not assemble into micelles. In fact, self-association of unmodified CDs is negligible and transient in aqueous solutions. ${ }^{4}$ CDs assemble into stable aggregated forms when they either form noncovalent inclusion complexes with hydrophobic guest molecules, where hydrophobic interactions between these molecules drive the assembly process, ${ }^{5}$ or when CDs are covalently modified by hydrophobic pendant groups. ${ }^{6}$

We developed a family of fluorinated dendritic nonionic amphiphiles, each comprising a hydrophobic dendron and a hydrophilic dendron. The hydrophobic dendron contains multiple chemically identical trifluoromethyl $\left(-\mathrm{CF}_{3}\right)$ groups, 
which act as the signal source for ${ }^{19} \mathrm{~F}$ NMR and MRI, while the hydrophilic dendron contains multiple chemically identical oligo-oxyethylene chains, which provide aqueous solubility. The hydrophobic dendron and the hydrophilic dendron are connected by amide bonds, which also contribute to aqueous solubility of the amphiphile. The dendrimers were developed as ${ }^{19} \mathrm{~F}$ Imaging Tracers and are denoted as ${ }^{19}$ FIT- $n$, with $n$ referring to the number of chemically identical fluorine atoms per dendrimer $\left(n=3^{2}, 3^{3}, 3^{4}, 3^{5} \ldots\right) \cdot{ }^{7,8}$ Fig. 1 shows the structure of ${ }^{19}$ FIT27. MRI studies in animals indicate that, as imaging agents, ${ }^{19}$ FIT-27 has many advantages over perfluorocarbons (e.g., perfluoro-octylbromide), including high water solubility ( $>150$ $\mathrm{mM}$ ), a singlet ${ }^{19} \mathrm{~F}$ signal from 27 magnetically equivalent fluorine atoms, low toxicity, and, most importantly, no excessive and prolonged accumulation in the liver and spleen. ${ }^{9}$ It is metabolically stable and is excreted primarily through the urine with an elimination $t_{1 / 2}$ of $\sim 12 \mathrm{~h}$. In contrast, perfluorocarbons accumulate excessively in the liver and spleen with an elimination $t_{1 / 2}$ on the order of 6 months or longer, ${ }^{10}$ are exhaled mainly through the lungs, and may cause fatal chemical pneumonitis. ${ }^{11}$

The NMR ${ }^{19} \mathrm{~F}$ chemical shift, $\delta\left({ }^{19} \mathrm{~F}\right)$, of two versions of ${ }^{19} \mathrm{FIT}$ 27 , which differ only by one $-\mathrm{CH}_{2}-$ group in the linker between the two dendrons, displays systematic up-field drift as their concentration $C\left({ }^{19}\right.$ FIT-27) increases. ${ }^{7,12}$ Initially, based on the plot of $\delta\left({ }^{19} \mathrm{~F}\right)$ vs. $1 / C\left({ }^{19} \mathrm{FIT}-27\right)$ alone, a method often used to determine CMC of surfactants, ${ }^{1,13}$ we concluded that ${ }^{19}$ FIT-27 forms micelles with a CMC around $8 \mathrm{mM}^{7,9}$ However, the magnitude of the $\delta\left({ }^{19} \mathrm{~F}\right)$ up-field shift is very small, $\sim 0.06 \mathrm{ppm}$, much smaller than that of conventional fluorinated amphiphiles, which are typically $\sim 1-2 \mathrm{ppm} .{ }^{13,14}$ To explore the reasons of such small magnitude of $\delta\left({ }^{19} \mathrm{~F}\right)$ up-field shift of ${ }^{19} \mathrm{FIT}-27$, we conducted more detailed characterizations of ${ }^{19}$ FIT-27 at three concentrations, 1, 10 and $100 \mathrm{mM}$-respectively below, around, and above the observed transition point $(\sim 8 \mathrm{mM})$. The assortment of structural and dynamic characterization techniques, including small-angle X-ray and neutron scattering (SAXS and SANS), dynamic light scattering (DLS) and NMR diffusometry (PFG NMR), have shown that ${ }^{19}$ FIT-27 remains monomeric as its concentration increases up to $100 \mathrm{mM}$. There is no aggregation. ${ }^{12}$

Based on our observations using the above listed methods, we proposed the following model for ${ }^{19}$ FIT-27. ${ }^{12}$ Instead of concentration-driven micellization/assembly, ${ }^{19}$ FIT-27 undergoes a concentration-driven conformational transition. At lower concentration, below $\sim 10 \mathrm{mM},{ }^{19}$ FIT-27 adopts an extended conformation, while at higher concentration, above $\sim 10 \mathrm{mM},{ }^{19}$ FIT-27 transitions to a compact conformation. Upon transition, the fluorocarbon moiety in ${ }^{19}$ FIT-27 is sequestered, at least to some extent, from water (Fig. 1). The inability of ${ }^{19}$ FIT27 to form micelles/assemblies probably stems from steric hindrances. It comprises two conical dendrons connected by a short linker; assembling doubly conical objects into conventional micelles might be spatially hindered. There are indeed examples of nonionic dendritic amphiphiles forming micelles,

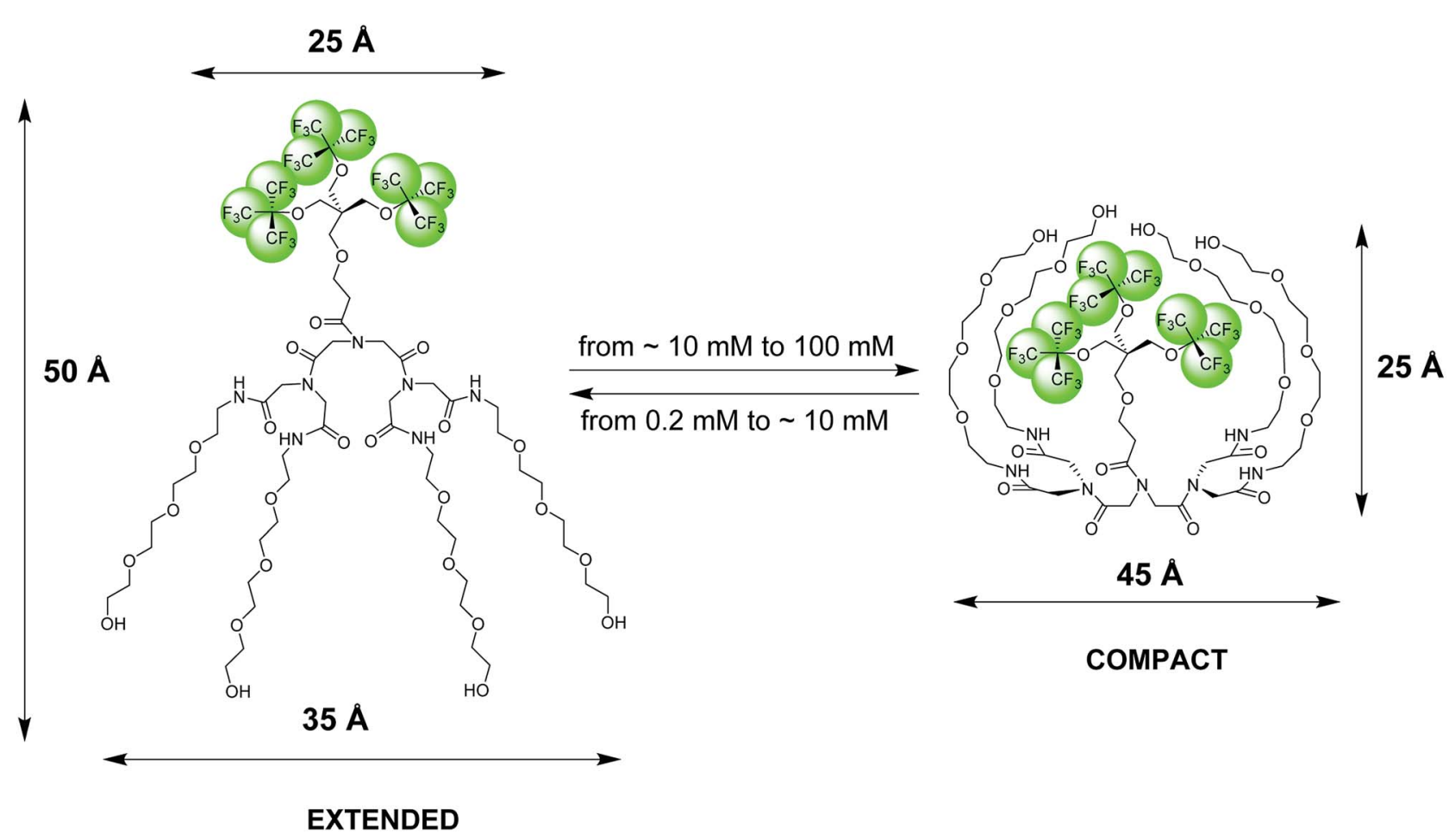

Fig. 1 Pictorial presentation of the structure and conformational transition of an amphiphilic fluorinated dendrimer, ${ }^{19} \mathrm{FIT}-27$, confirmed by SAXS, SANS, DLS, and NMR diffusometry data. ${ }^{12}$ The extended conformation dominates at low dendrimer concentrations $(<10 \mathrm{mM})$ while the compact conformation dominates at high dendrimer concentrations $(>10 \mathrm{mM})$. The dimensional parameters of the extended and compact forms of ${ }^{19} \mathrm{FIT}-$ 27 are from the SAXS data. ${ }^{12}$ 
but they comprise a single conical dendron and a linear tail, a shape compatible with tight packing for micellization. ${ }^{15}$

The conclusion that an amphiphile undergoes a concentration-dependent conformational transition instead of micellization is surprising. To our knowledge, it has not been reported before and, therefore, warrants further investigation. The nature of the transition can be clarified directly, if highresolution structures of ${ }^{19}$ FIT-27 at various concentrations are available. This, however, proves an elusive goal to us thus far.

In this work, we aim to strengthen the conclusion regarding the conformational transition of ${ }^{19}$ FIT-27 based on a repertoire of techniques different from those used in our previous study. ${ }^{\mathbf{1 2}}$ Here, we compared the concentration-dependent transition of ${ }^{19}$ FIT-27 with the behavior of another fluorinated amphiphile, sodium perfluorooctanoate $\left(\mathrm{NaFC}_{8}\right)$, which is known to form micelles. We found that micellization/assembly results in orders of magnitude larger changes in ${ }^{19} \mathrm{~F}$ chemical shifts as compared to the transition of ${ }^{19}$ FIT-27, suggesting that ${ }^{19}$ FIT-27 does not undergo micellization.

We have previously shown that the transverse relaxation rate of water protons, $R_{2}\left({ }^{1} \mathrm{H}_{2} \mathrm{O}\right)$, is sensitive to a number of structural transformations of solutes, including the micellization of amphiphiles. ${ }^{16}$ Since $R_{2}\left({ }^{1} \mathrm{H}_{2} \mathrm{O}\right)$ is affected by the proton exchange rates between water and solute molecules, the assembly of solute molecules will affect their proton exchange with water, resulting in a subsequent change in $R_{2}\left({ }^{1} \mathrm{H}_{2} \mathrm{O}\right)$. Here, we compared the concentration-dependent profile of $R_{2}\left({ }^{1} \mathrm{H}_{2} \mathrm{O}\right)$ of ${ }^{19}$ FIT-27 with those of sodium octanoate $\left(\mathrm{NaC}_{8}\right)$ and $\alpha$-CD. $\mathrm{NaC}_{8}$ is known to form micelle as its concentration increases while $\alpha$-CD is known to undergo neither micellization nor conformational transition as its concentration increases. We observed that $R_{2}\left({ }^{1} \mathrm{H}_{2} \mathrm{O}\right)$ of both ${ }^{19}$ FIT-27 and $\mathrm{NaC}_{8}$ display nonlinear dependence on solute concentration with clear transition points while that of $\alpha$-CD display linear dependence on solute concentration with no transition point. However, $R_{2}\left({ }^{1} \mathrm{H}_{2} \mathrm{O}\right)$ of ${ }^{19}$ FIT-27 and $\mathrm{NaC}_{8}$ follow opposite trends, suggesting they undergo different types of concentrationdependent transitions.

We also monitored the concentration-dependent behavior of ${ }^{19}$ FIT-27 using ion-mobility mass-spectrometry (IM-MS). Since the drift time in IM-MS is defined by the collision cross-section of an ion in the gas phase, IM-MS data can provide comparative information on the relative dimensional and shape changes of ions. Indeed, e.g., for proteins, it has been demonstrated that under gentle ionization, many proteins typically retain their shape and compactness also in the gas phase. ${ }^{17}$ We found that during ionization, ${ }^{19}$ FIT-27 similarly retains its solution phase shape with no indications of the supramolecular assembly which would have led to longer drift time at higher concentrations. Instead, the opposite occurred - the drift time of ${ }^{19}$ FIT-27 becomes shorter at higher concentrations, suggesting compaction, rather than aggregation, as the dendrimer concentration increases.

Thus, the combination of results from multiple analytical techniques clearly points to the concentration-dependent conformational transition of the fluorinated dendrimer ${ }^{19}$ FIT27 rather than micellization and/or other supramolecular assembly. In the compact form of ${ }^{19}$ FIT-27, the hydrophobic $\mathrm{CF}_{3}$-groups are sequestered, albeit incompletely, from water.

\section{Results and discussion}

\section{Summary of structural characterizations of ${ }^{19}$ FIT-27}

From our previous work, ${ }^{12}$ we made three related conclusions about the concentration-dependent behavior of ${ }^{19}$ FIT-27: (i) it does not undergo micellization/assembly; (ii) its structure becomes more compact as its concentration increases; and (iii) it experiences significant inter-molecular interactions at high concentration. The experimental observations corroborating each of the above conclusions are briefly summarized below.

(i) Our conclusion that ${ }^{19}$ FIT-27 does not form micelles/ assemblies was based on the following evidence. First, SAX(N)S (small-angle X-ray or neutron scattering) scattering profiles $^{12}$ showed no signs of micellization/assembly. Indeed, the $\log I(Q) v s . \log Q$ plots for $1 \mathrm{mM}, 10 \mathrm{mM}$, and $100 \mathrm{mM}$ concentrations of ${ }^{19}$ FIT-27 were flat in the low region of the scattering vector $Q$-in case of assembly, $I(Q)$ is known to show steep growth in the low $Q$ region. ${ }^{18}$ Moreover, the low-resolution 3D-shape of ${ }^{19}$ FIT-27 molecule reconstructed from SAXS data showed comparable dimensional characteristics ${ }^{12}$ of ${ }^{19}$ FIT-27 at $1 \mathrm{mM}, 10 \mathrm{mM}$, and $100 \mathrm{mM}$, also suggesting no assembly. Second, DLS (dynamic light scattering) data suggested that ${ }^{19}$ FIT-27 had very close values of hydrodynamic radii $R_{\mathrm{h}}$ at $1 \mathrm{mM}, 10 \mathrm{mM}$, and $100 \mathrm{mM}$ (31 А, $33 \AA$, and $34 \AA$, respectively), suggesting there is no assembly. ${ }^{12}$ The slight increase in $R_{\mathrm{h}}$ at higher concentrations might reflect somewhat slower motion of the individual ${ }^{19}$ FIT-27 molecules. Third, the self-diffusion coefficient of ${ }^{19}$ FIT-27 normalized by water diffusion to account for viscosity effects, $D\left({ }^{19}\right.$ FIT-27 $) / D\left({ }^{1} \mathrm{H}_{2} \mathrm{O}\right)$-both were measured by PFG (pulsed field gradient) NMR-decreases slightly from 0.036 at $1 \mathrm{mM}$ to 0.034 at $10 \mathrm{mM} \cdot{ }^{12}$ If ${ }^{19}$ FIT-27 molecules assemble around $10 \mathrm{mM}$, one would expect a much larger decrease of $D_{\mathrm{s}}\left({ }^{19}\right.$ FIT-27) $/ D_{\mathrm{s}}\left({ }^{1} \mathrm{H}_{2} \mathrm{O}\right)$. At $100 \mathrm{mM}, D_{\mathrm{s}}\left({ }^{19}\right.$ FIT27) $/ D_{\mathrm{s}}\left({ }^{1} \mathrm{H}_{2} \mathrm{O}\right)$ indeed decreases more significantly, to $0.020 .{ }^{12}$ This is more likely due to the crowding effect at $100 \mathrm{mM}$ rather than assembly, which is discussed in the details below.

(ii) Two observations suggested that the ${ }^{19}$ FIT-27 molecule is more compact at $10 \mathrm{mM}$ and $100 \mathrm{mM}$ than at $1 \mathrm{mM}$. First, SAXS data showed that ${ }^{19}$ FIT-27 has a smaller radius of gyration $R_{\mathrm{g}}$ at $10 \mathrm{mM}(17.2 \AA)$ than at $1 \mathrm{mM}(17.8 \AA) .{ }^{12}$ Second, particle size distributions from DLS showed that ${ }^{19}$ FIT-27 has a broader distribution of $R_{\mathrm{h}}$ at $1 \mathrm{mM}$ than at 10 and $100 \mathrm{mM}$, suggesting ${ }^{19}$ FIT-27 is more flexible and could sample more conformations at $1 \mathrm{mM}$ than at $10 \mathrm{mM}$ and $100 \mathrm{mM}$. This is consistent with ${ }^{19}$ FIT-27 existing in an extended more flexible conformation at $1 \mathrm{mM}$, but in a more compact conformation at 10 and $100 \mathrm{mM}^{\mathbf{1 2}}$

(iii) Finally, we concluded that inter-molecular interactions between ${ }^{19}$ FIT-27 molecules are negligible at $1 \mathrm{mM}$ and $10 \mathrm{mM}$, but become pronounced at $100 \mathrm{mM}$. First, in both SAXS and SANS scattering profiles, ${ }^{12}$ a broad peak corresponding to the distances between ${ }^{19}$ FIT-27 molecules $\sim 70 \AA$, was observed at $100 \mathrm{mM}$, but absent at 1 and $10 \mathrm{mM}$, and is a clear evidence of strong interparticle interference. Second, at all three concentrations, DLS data of ${ }^{19}$ FIT-27 display a peak in the $\mu$ s range. 
However, at $100 \mathrm{mM}$, DLS data display an additional peak that is absent at 1 and $10 \mathrm{mM}$. This peak is in the ms time range, which suggests slow cooperative motion of ${ }^{19}$ FIT-27 molecules at $100 \mathrm{mM} .{ }^{12}$ Third, the normalized self-diffusion coefficient of ${ }^{19}$ FIT-27, $D_{\mathrm{s}}\left({ }^{19}\right.$ FIT-27) $/ D_{\mathrm{s}}\left({ }^{1} \mathrm{H}_{2} \mathrm{O}\right)$, decreased from 0.034 at $10 \mathrm{mM}$ to 0.020 at $100 \mathrm{mM}$, suggesting the diffusion of ${ }^{19}$ FIT-27 is hindered at $100 \mathrm{mM}$. Fourth, the ratio between the collective diffusion coefficient of ${ }^{19}$ FIT-27, $D_{c}\left({ }^{19}\right.$ FIT-27), determined by DLS, and the self-diffusion coefficient of ${ }^{19}$ FIT-27, $D_{\mathrm{s}}\left({ }^{19}\right.$ FIT-27), determined by PFG NMR, increased from $c a .1 .2$ at $1 \mathrm{mM}$ and $10 \mathrm{mM}$ to $c a .2 .3$ at $100 \mathrm{mM}$. Such an increase in the ratio between two diffusion coefficients is known $^{19}$ to be an indication of much stronger inter-particle interactions, as observed when the concentration of ${ }^{19}$ FIT-27 increases from $10 \mathrm{mM}$ to $100 \mathrm{mM}^{12}$

In this work, we address additional details of the concentration-dependent conformational transition of ${ }^{19}$ FIT27. Particular attention is on the extent of shielding of the fluorocarbon moiety from water upon conformational transition and on the driving force of the transition. Also, mass spectrometry is employed to verify conformational transition $v s$. supramolecular assembly as the concentration of ${ }^{19}$ FIT-27 increases.

\section{Concentration-dependent transition of ${ }^{19}$ FIT-27 vs. assembly of $\mathrm{NaFC}_{8}$}

To clarify the differences between conformational transition and micellization/assembly, we compared the concentrationdependent behavior of the fluorinated amphiphilic dendrimer, ${ }^{19}$ FIT-27, with a well-characterized fluorinated amphiphile, sodium perfluorooctanoate $\left(\mathrm{NaFC}_{8}\right)$. As a reference molecule, $\mathrm{NaFC}_{8}$ can shed light on two aspects of ${ }^{19}$ FIT-27. First, how shielded are the fluorocarbons in ${ }^{19}$ FIT-27 from water in the compact state? The aliphatic fluorocarbon chain of $\mathrm{NaFC}_{8}$, ${ }^{19} \mathrm{~F}_{3} \mathrm{C}^{8}-{ }^{19} \mathrm{~F}_{2} \mathrm{C}^{7}-{ }^{19} \mathrm{~F}_{2} \mathrm{C}^{6}-{ }^{19} \mathrm{~F}_{2} \mathrm{C}^{5}-{ }^{19} \mathrm{~F}_{2} \mathrm{C}^{4}-{ }^{19} \mathrm{~F}_{2} \mathrm{C}^{3}-{ }^{19} \mathrm{~F}_{2} \mathrm{C}^{2}$-, is buried to a differing extent in the micelle core, with the ${ }^{19} \mathrm{~F}_{3} \mathrm{C}^{8}$-group the deepest and the ${ }^{19} \mathrm{~F}_{2} \mathrm{C}^{2}$-group the shallowest. Only the ${ }^{19} \mathrm{~F}_{2} \mathrm{C}^{2}$-group, adjacent to the carboxylate head group, has contact with water according to NMR relaxation data. ${ }^{\mathbf{1 4 , 2 0}}$ According to SANS data, no water is present in the center of $\mathrm{NaFC}_{8}$ micelles. ${ }^{21}$ In other words, sequestration of water from the micellar core of $\mathrm{NaFC}_{8}$ is rather complete. This feature makes $\mathrm{NaFC}_{8}$ an ideal reference point to assess the sequestration of fluorocarbon groups from water in ${ }^{19}$ FIT-27. Second, $\mathrm{NaFC}_{8}$ forms micelles with a CMC of $30-32 \mathrm{mM}$ at $25{ }^{\circ} \mathrm{C},{ }^{13}$ and increasing to $36 \mathrm{mM}$ at $8{ }^{\circ} \mathrm{C}^{21}$ Its aggregation number, $N$, referring to number of monomers per micelle, increases with concentration and reaches 23 at its $\mathrm{CMC}$ at $25{ }^{\circ} \mathrm{C}^{22}$ Concentration-dependent assembly of $23 \mathrm{NaFC}_{8}$ molecules is a much more cooperative process as compared to the conformational transition of a single ${ }^{19}$ FIT-27 molecule.

The concentration-dependent transitions for ${ }^{19}$ FIT-27 and $\mathrm{NaFC}_{8}$ were monitored using the ${ }^{19} \mathrm{~F}$ chemical shift, $\delta\left({ }^{19} \mathrm{~F}\right)$. Previously, the micellization of $\mathrm{NaFC}_{8}$ was characterized using its $\delta\left({ }^{19} \mathrm{~F}\right)$ changes at $35{ }^{\circ} \mathrm{C}$ and $1.41 \mathrm{~T}\left(56.4 \mathrm{MHz}\right.$ for $\left.{ }^{19} \mathrm{~F}\right) .{ }^{13} \mathrm{We}$ measured $\delta\left({ }^{19} \mathrm{~F}\right)$ of ${ }^{19}$ FIT-27 and $\mathrm{NaFC}_{8}$ at $22{ }^{\circ} \mathrm{C}$ and $9.4 \mathrm{~T}(376.5$
MHz for ${ }^{19} \mathrm{~F}$ ). All 27 fluorine atoms in ${ }^{19}$ FIT-27 are magnetically equivalent and thereby emit a single un-split ${ }^{19} \mathrm{~F}$ signal. In contrast, 15 fluorine atoms in the perfluorocarbon chain of $\mathrm{NaFC}_{8}$ are not magnetically equivalent, and thereby emit multiple ${ }^{19} \mathrm{~F}$ signals. Of the seven fluorocarbon groups in $\mathrm{NaFC}_{8},{ }^{19} \mathrm{~F}_{3} \mathrm{C}^{8}$ - and $-{ }^{19} \mathrm{~F}_{2} \mathrm{C}^{2}$-groups are respectively distal and proximal to the polar carboxylic group, wherein the former is closest to the center of micellar core, while the latter is farthest from the core. We, therefore, chose $\delta\left({ }^{19} \mathrm{~F}_{3} \mathrm{C}^{8}-\right)$ and $\delta\left(-{ }^{19} \mathrm{~F}_{2} \mathrm{C}^{2}-\right)$ chemical shifts to monitor the micellization of $\mathrm{NaFC}_{8}$. Fig. 2 shows concentration-dependent changes of chemical shifts $\delta\left({ }^{19} \mathrm{~F}_{3} \mathrm{C}-\right)$ for ${ }^{19} \mathrm{FIT}-27$, and $\delta\left({ }^{19} \mathrm{~F}_{3} \mathrm{C}^{8}-\right)$ and $\delta\left(-{ }^{19} \mathrm{~F}_{2} \mathrm{C}^{2}-\right)$ for $\mathrm{NaFC}_{8}$. The data are plotted in two ways. One is $\delta\left({ }^{19} \mathrm{~F}\right)$ vs. $1 / C$ (solute), which is a commonly used method to determine CMC of amphiphiles, ${ }^{23}$ and has been previously applied to $\mathrm{NaFC}_{8}{ }^{13}$ Another is $\delta\left({ }^{19} \mathrm{~F}\right)$ vs. $C$ (solute), which is used in more recent work to determine CMC of amphiphiles. ${ }^{24}$

In the $\delta\left({ }^{19} \mathrm{~F}\right)$ vs. $1 / C$ (solute) plot, the transition, for both ${ }^{19}$ FIT-27 and $\mathrm{NaFC}_{8}$, appears more salient than in the $\delta\left({ }^{19} \mathrm{~F}\right) v s$. $C$ (solute) plot. This difference between these two ways to plot data on amphiphiles has been observed before, ${ }^{23}$ and perhaps accounts for the prevalence of plotting a physical chemical parameter of the amphiphile vs. 1/C(amphiphile) to extract CMC of amphiphiles. We initially concluded that two versions of ${ }^{19}$ FIT-27 form micelles with CMC of $c a .8 \mathrm{mM}$ based on $\delta\left({ }^{19} \mathrm{~F}\right)$ vs. $1 / C$ (solute) plots. $^{7,9}$ Absent from our previous work was a side-by-side comparison with a known micelle-forming amphiphile. Here, with the $\delta\left({ }^{19} \mathrm{~F}\right)$ vs. $1 / C$ (solute) plots of ${ }^{19}$ FIT27 and $\mathrm{NaFC}_{8}$ presented together, it can be seen that ${ }^{19}$ FIT-27 displays a much less cooperative transition compared to $\mathrm{NaFC}_{8}$ (Fig. 2(A)-(C)). In the $\delta\left({ }^{19} \mathrm{~F}\right)$ vs. $C$ (solute) plot, the transition of ${ }^{19}$ FIT-27 appears even more diffusive (Fig. 2(D)-(F)). These results suggest that the concentration-dependent transition of ${ }^{19}$ FIT-27 is much less cooperative than that of $\mathrm{NaFC}_{8}$, which is known to involve 23 molecules. Although this does not prove that the transition of ${ }^{19}$ FIT-27 is monomeric, it does suggest that it involves much less than 23 molecules.

In all three $\delta\left({ }^{19} \mathrm{~F}\right)$ vs. $C$ (solute) profiles, transition results in the upfield shift of $\delta\left({ }^{19} \mathrm{~F}\right)$. Greater shielding of ${ }^{19} \mathrm{~F}$ nuclei from external magnetic field is known to result in the upfield shift of $\delta\left({ }^{19} \mathrm{~F}\right)$, when the environment of fluorocarbon groups become less polar. ${ }^{25}$ Thus, in all cases, the upfield shift of $\delta\left({ }^{19} \mathrm{~F}\right)$ of the fluorocarbon groups is consistent with their transition from a more polar environment to a less polar environment. In other words, the concentration-dependent transitions in both ${ }^{19}$ FIT27 and $\mathrm{NaFC}_{8}$ result in a sequestration of the fluorocarbon groups from water to some extent.

As we have already mentioned, the micellization of $\mathrm{NaFC}_{8}$ results in complete sequestration of its ${ }^{19} \mathrm{~F}_{3} \mathrm{C}^{8}$-groups from water. ${ }^{21}$ The tight packing of the core of $\mathrm{NaFC}_{8}$ micelles also excludes the effects of $\mathrm{Na}^{+}$-counterion on the chemical shifts of deeply buried ${ }^{19} \mathrm{~F}_{3} \mathrm{C}^{8}$-groups. Therefore, had the fluorocarbon groups in ${ }^{19}$ FIT-27 been completely sequestered from water and $\mathrm{Na}^{+}$-ions upon its concentration-dependent transition, the extent of the upfield shift of $\delta\left({ }^{19} \mathrm{~F}\right)$ of these groups would have been comparable to that of $\mathrm{NaFC}_{8}$. However, the magnitude of the upfield shift of $\delta\left({ }^{19} \mathrm{~F}\right)$ is very different all three cases (Fig. 2). At $22{ }^{\circ} \mathrm{C}$, the magnitude of $\delta\left({ }^{19} \mathrm{~F}\right)$ 
(A)

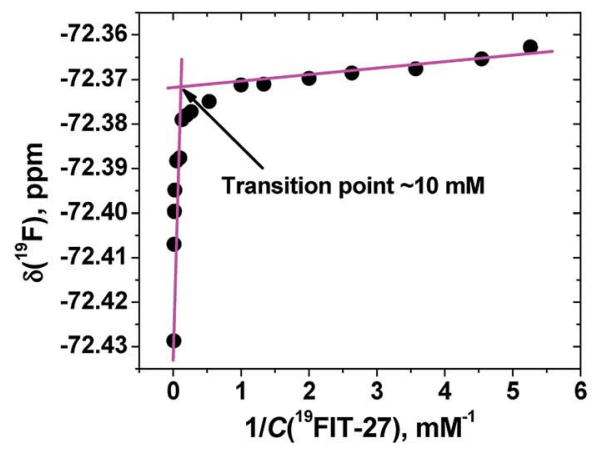

(D)

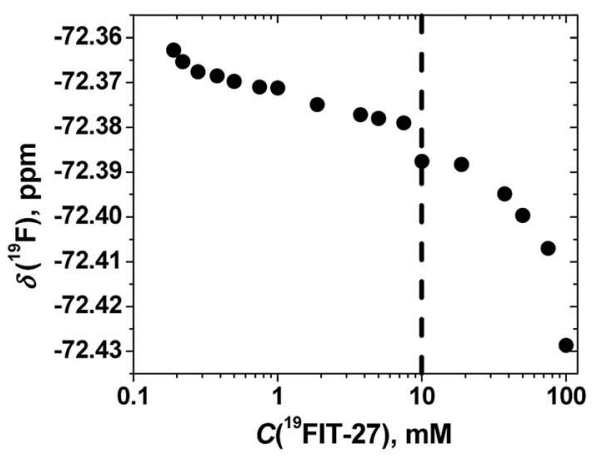

(B)

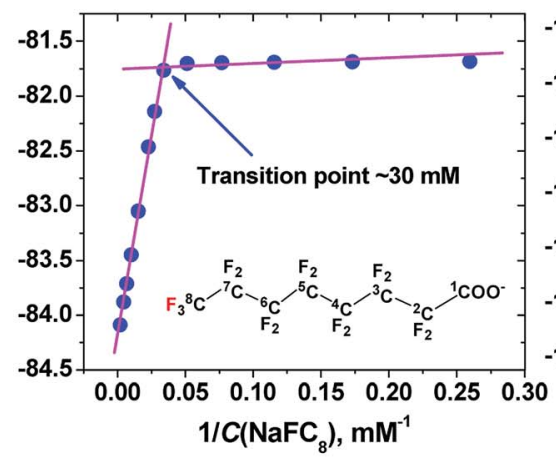

(E)

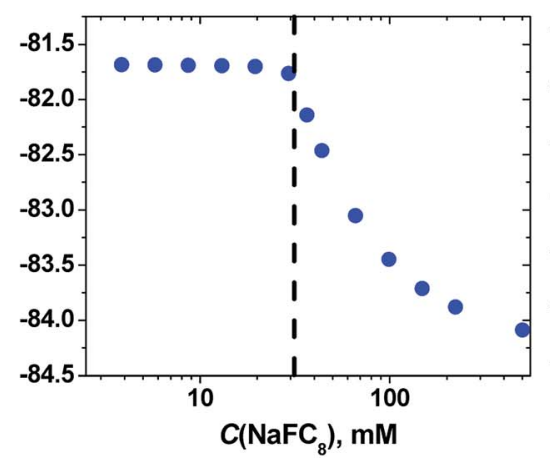

(C)

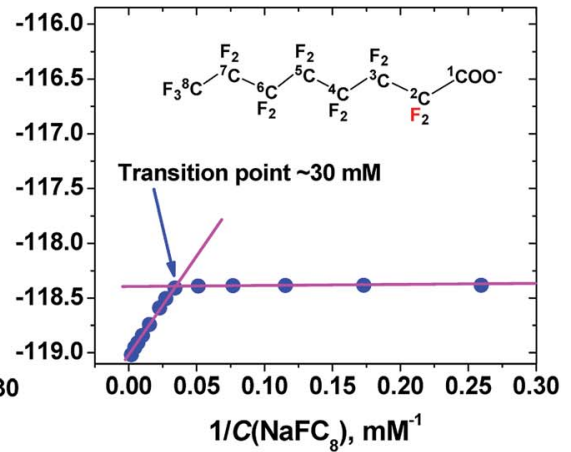

(F)

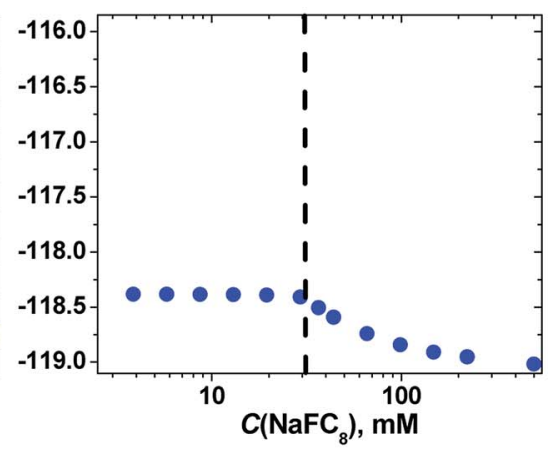

Fig. 2 Comparison of the concentration-dependent transitions of ${ }^{19} \mathrm{FIT}-27$ and $\mathrm{NaFC}$ monitored by the ${ }^{19} \mathrm{~F}$ chemical shift $\delta\left({ }^{19} \mathrm{~F}\right)$ measured at 9.4 $\mathrm{T}$ and $22{ }^{\circ} \mathrm{C}$. Top row $-\delta\left({ }^{19} \mathrm{~F}\right)$ vs. $1 / \mathrm{C}$ (solute). (A) $\delta\left({ }^{19} \mathrm{~F}_{3} \mathrm{C}-\right)$ for ${ }^{19} \mathrm{FIT}-27$; (B) $\delta\left({ }^{19} \mathrm{~F}_{3} \mathrm{C}^{8}-\right)$ for $\mathrm{NaFC}_{8}$ (red label); (C) $\delta\left(-{ }^{19} \mathrm{~F}_{2} \mathrm{C}^{2}-\right)$ for $\mathrm{NaFC} \mathrm{C}_{8}($ red label). The two segments in each plot are fitted to linear lines (magenta) and the crossing point of the two lines gives the transition point (shown in each panel). Bottom row- $\delta\left({ }^{19} \mathrm{~F}\right)$ vs. C(solute). (D) $\delta\left({ }^{19} \mathrm{~F}_{3} \mathrm{C}-\right.$ ) for ${ }^{19} \mathrm{FIT}-27 ;(\mathrm{E}) \delta\left({ }^{19} \mathrm{~F}_{3} \mathrm{C}^{8}-\right)$ for $\mathrm{NaFC}_{8} ;(\mathrm{F}) \delta\left(-{ }^{19} \mathrm{~F}_{2} \mathrm{C}^{2}-\right)$ for $\mathrm{NaFC}$. C(solute) is shown in the logarithmic scale so that the transition point for each process is better revealed. The concentration range for ${ }^{19} \mathrm{FIT}-27$ is $0.2-100 \mathrm{mM}(0.4-$ $\left.190 \mathrm{mg} \mathrm{mL}^{-1}\right)$; that for $\mathrm{NaFC}_{8}$ is $3.9-500 \mathrm{mM}\left(1.8-231.5 \mathrm{mg} \mathrm{mL}^{-1}\right)$.

upfield shift is $\sim 0.06 \mathrm{ppm}$ for ${ }^{19} \mathrm{FIT}-27$ (Fig. 2(A) and (D)), $\sim 2.5 \mathrm{ppm}$ for ${ }^{19} \mathrm{~F}_{3} \mathrm{C}^{8}$ - (Fig. 2(B) and (E)), and $\sim 0.6 \mathrm{ppm}$ for $-{ }^{19} \mathrm{~F}_{2} \mathrm{C}^{2}$ - (Fig. 2(C) and (F)). The smaller upfield shift of $-{ }^{19} \mathrm{~F}_{2} \mathrm{C}^{2}$ groups compared to ${ }^{19} \mathrm{~F}_{3} \mathrm{C}^{8}$-groups in $\mathrm{NaFC}_{8}$ is due to the location of the former closer to the micelle surface and their partial exposure to water. The ${ }^{19} \mathrm{~F}_{3} \mathrm{C}^{8}$-groups which are completely sequestered from water upon micellization, ${ }^{14,20}$ demonstrate a much larger upfield shift (cf., e.g., Fig. 2(B) and (C)). Therefore, the much smaller upfield shift of $\delta\left({ }^{19} \mathrm{~F}_{3} \mathrm{C}-\right)$ of ${ }^{19} \mathrm{FIT}-27$ upon transition suggests that the sequestration of its fluorocarbon groups from water is very incomplete compared to $\mathrm{NaFC}_{8}$ micellization.

Comparison with $\mathrm{NaFC}_{8}$ confirms that ${ }^{19}$ FIT-27 indeed undergoes a concentration-dependent transition, but this transition process is much less pronounced than in the case of $\mathrm{NaFC}_{8}$ micellization, and the water molecules still interact with the fluorocarbon groups of ${ }^{19}$ FIT-27 in its compact state. Although the sequestration is rather incomplete, one might still expect that water will interact with the extended and compact forms of ${ }^{19}$ FIT27 differently, i.e., water might differentiate different conformations of the dendrimer. In light of our previous work, where we demonstrated that the water proton transverse relaxation rate, $R_{2}\left({ }^{1} \mathrm{H}_{2} \mathrm{O}\right)$, is sensitive to solute-water interaction, ${ }^{16}$ we explored whether the concentration-dependent transition of ${ }^{19}$ FIT-27 can be monitored by $R_{2}\left({ }^{1} \mathrm{H}_{2} \mathrm{O}\right)$.
Water proton transverse relaxation rate $R_{2}\left({ }^{1} \mathrm{H}_{2} \mathrm{O}\right)$ as a probe of transition $v s$. assembly

As we have already mentioned, the sensitivity of water proton transverse rate, $R_{2}\left({ }^{1} \mathrm{H}_{2} \mathrm{O}\right)$, to the efficiency of proton exchange between solute and water molecules, makes it a potent probe of concentration-dependent behavior of solutes. ${ }^{16}$ Indeed, the conformational transitions and/or micellization/assembly of amphiphiles are expected to affect their proton exchange with water resulting in the changes of $R_{2}\left({ }^{1} \mathrm{H}_{2} \mathrm{O}\right)$.

We, therefore, compared concentration-dependent changes of $R_{2}\left({ }^{1} \mathrm{H}_{2} \mathrm{O}\right)$ for ${ }^{19}$ FIT-27 (in the range $0.2-100 \mathrm{mM}(0.4-190 \mathrm{mg}$ $\left.\mathrm{mL}^{-1}\right)$ ) and a known micelle-forming amphiphile, sodium octanoate $\left(\mathrm{NaC}_{8}\right)$ (in the range 9-2400 $\mathrm{mM}\left(1.5-400 \mathrm{mg} \mathrm{mL}^{-1}\right)$ ). $\mathrm{NaC}_{8}$ forms micelles with two CMCs, one in the range 0.3-0.4 M and another in the range 0.9-1.2 M. Its aggregation number $N$ is not fixed, but rather increases from 10-15 to 20-25 with increasing concentration of $\mathrm{NaC}_{8}{ }^{26} \mathrm{Here}$, we also used a third amphiphile, $\alpha-\mathrm{CD}$, as a benchmark for $R_{2}\left({ }^{1} \mathrm{H}_{2} \mathrm{O}\right)$ concentrationdependent response, since $\alpha$-CD is known not to form micelles and is not prone to any conformational transitions within its studied concentration range $(0.2-105 \mathrm{mM} \quad(0.2-102 \mathrm{mg}$ $\left.\left.\mathrm{mL}^{-1}\right)\right){ }^{27}$ In the essence, $\alpha$-CD serves as a negative control for both micellization and conformational transition. 
For the purpose of comparing the three amphiphiles, we normalized both $R_{2}\left({ }^{1} \mathrm{H}_{2} \mathrm{O}\right)$ and $C$ (solute), using the following formula to obtain corresponding $X_{\text {normalized }}$ values

$$
X_{\text {normalized }}=\frac{X_{\mathrm{i}}-X_{\min }}{X_{\max }-X_{\min }},
$$

where $X_{\mathrm{i}}$ is the experimental value of $R_{2}\left({ }^{1} \mathrm{H}_{2} \mathrm{O}\right)$ or $C$ (solute), respectively; $X_{\min }$ is the minimum value of $R_{2}\left({ }^{1} \mathrm{H}_{2} \mathrm{O}\right)$ or $C$ (solute), respectively; and $X_{\max }$ is the maximum values of $R_{2}\left({ }^{1} \mathrm{H}_{2} \mathrm{O}\right)$ or $C$ (solute), respectively. As a result of such normalization, the range of $R_{2}\left({ }^{1} \mathrm{H}_{2} \mathrm{O}\right)$ or $C$ (solute) variations for all three amphiphiles will span from 0 to 1 (see ESI Table S1 and Fig. S1 $\dagger$ for the raw data before normalization and Table S2 $\uparrow$ for data after normalization).

As seen from Fig. 3(A), in the absence of micellization/ assembly and any conformational transitions affecting solutewater interactions, such as in the case of $\alpha$-CD, the normalized dependence of $R_{2}\left({ }^{1} \mathrm{H}_{2} \mathrm{O}\right)$ vs. $C$ (solute) is linear without any transition point. A linear relationship between $R_{2}\left({ }^{1} \mathrm{H}_{2} \mathrm{O}\right)$ and the proton molar fraction of $\alpha$-CD has been reported, ${ }^{28}$ and is consistent with our observations. However, the plots $R_{2}\left({ }^{1} \mathrm{H}_{2} \mathrm{O}\right)$ vs. $C$ (solute) for two other amphiphiles deviate from linearity and show evident transition points around a CMC value $\left(\mathrm{NaC}_{8}\right)$ or a conformational transition $\left({ }^{19} \mathrm{FIT}-27\right)$. The linear behavior of $\alpha$-CD, the negative control, demonstrates that the observed nonlinear transition of $\mathrm{NaC}_{8}$ and ${ }^{19} \mathrm{FIT}-27$ is not simply due to increasing fraction of water molecules in the hydration shell of the solute as $C$ (solute) increases.

In Fig. 3(A), opposite concentration-dependent trends of $R_{2}\left({ }^{1} \mathrm{H}_{2} \mathrm{O}\right)$ were observed for micellization/assembly $\left(\mathrm{NaC}_{8}\right)$ and conformational transition $\left({ }^{19}\right.$ FIT-27). Indeed, $R_{2}\left({ }^{1} \mathrm{H}_{2} \mathrm{O}\right)$ of $\mathrm{NaC}_{8}$ shows initially positive deviation and then negative deviation from the linear trend of $\alpha$-CD, while $R_{2}\left({ }^{1} \mathrm{H}_{2} \mathrm{O}\right)$ of ${ }^{19}$ FIT-27 shows negative deviation in the entire concentration range (Fig. 3(A)). This contrast between the three amphiphiles is better visualized in the difference plot shown in Fig. 3(B), where the linear $\alpha$-CD dependence is subtracted from all three $R_{2}\left({ }^{1} \mathrm{H}_{2} \mathrm{O}\right) v s$. $C$ (solute) plots. The positive deviation of $\mathrm{NaC}_{8}$ from linearity occurs near its $1^{\text {st }}$ transition point, which is attributed to micelle formation, while the negative deviation occurs near its $2^{\text {nd }}$ transition point, which is attributed to the structural reorganization ${ }^{29}$ of the already assembled micelles to reduce the crowding at such high concentrations. ${ }^{30}$ In essence, the $2^{\text {nd }}$ transition of $\mathrm{NaC}_{8}$ is a conformational transition at the micellar level, analogous to the conformational transition of ${ }^{19}$ FIT-27 at the molecular level. The common feature for both is that the normalized $R_{2}\left({ }^{1} \mathrm{H}_{2} \mathrm{O}\right)$ displays negative deviation from the linear behavior of $\alpha$-CD.

These observations show that sequestration of hydrophobic groups from water indeed alters $R_{2}\left({ }^{1} \mathrm{H}_{2} \mathrm{O}\right)$, whether the sequestration is complete (as in $\mathrm{NaC}_{8}$ ) or incomplete (as in ${ }^{19}$ FIT-27). Distinctive behavior of normalized $R_{2}\left({ }^{1} \mathrm{H}_{2} \mathrm{O}\right)$ vs. $C$ (solute) for micellization/assembly and conformational transitions makes it possible to distinguish between these two types of concentration-dependent transitions. However, the generality of the observation that supramolecular assembly leads to positive deviation of normalized $R_{2}\left({ }^{1} \mathrm{H}_{2} \mathrm{O}\right)$ from linearity and monomeric conformational transition leads to negative deviation of normalized $R_{2}\left({ }^{1} \mathrm{H}_{2} \mathrm{O}\right)$ from linearity remains to be seen.

Sequestration of the $-\mathrm{CF}_{3}$ groups in ${ }^{19}$ FIT-27 upon transition is presumably due to compaction of the dendrimer. To verify, we used ion-mobility mass-spectrometry (IM-MS) to monitor the structural dimension of ${ }^{19}$ FIT-27 as its concentration increases.

\section{Transition $v s$. assembly of ${ }^{19}$ FIT-27 from the perspective of mass-spectrometry}

No assemblies of ${ }^{19}$ FIT-27 observed in ESI-MS. Recently, it has been shown that electrospray ionization mass-spectrometry (ESI-MS) could be advantageously used to study assembly and/ or self-assembly processes driven by weak hydrophobic interactions, such as protein oligomerization ${ }^{31}$ and peptide selfassembly. ${ }^{32}$ There is also a plethora of evidences demonstrating
(A)

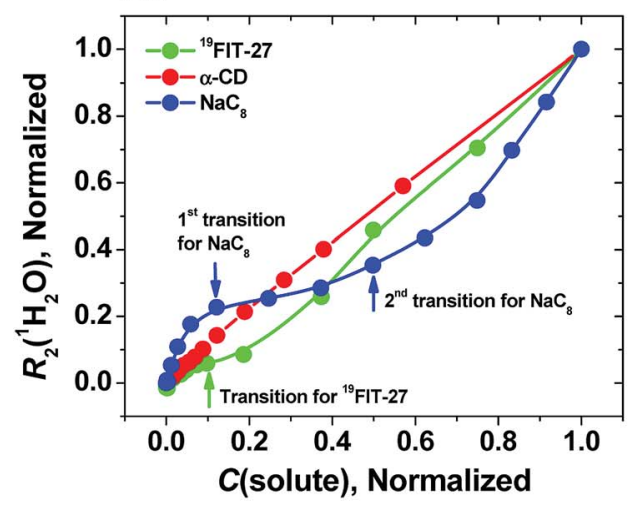

(B)

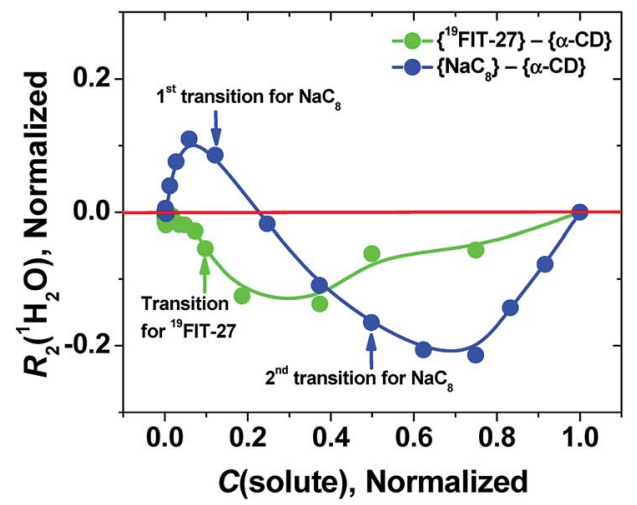

Fig. 3 Sensitivity of water proton transverse relaxation rate, $R_{2}\left({ }^{1} \mathrm{H}_{2} \mathrm{O}\right)$, towards conformational transitions and/or assembly of amphiphiles. (A) Comparative normalization plots of $R_{2}\left({ }^{1} \mathrm{H}_{2} \mathrm{O}\right)$ vs. C(solute) for three amphiphiles $\left(-\bullet-{ }^{19} \mathrm{FIT}-27,-\bullet-\alpha-\mathrm{CD},-\bullet-\mathrm{NaC}\right)$; (B) difference plots using data in (A) showing opposite deviations from linearity for transition vs. assembly $\left(-\bullet-\left\{{ }^{19} \mathrm{FIT}-27\right\}-\{\alpha-\mathrm{CD}\},-\bullet-\{\mathrm{NaC}\}-\{\alpha-\mathrm{CD}\}\right)$. Arrows show corresponding transition points for $\mathrm{NaC}_{8}$ and ${ }^{19} \mathrm{FIT}-27$. The absolute values for the $1^{\text {st }}$ and $2^{\text {nd }}$ transition points for $\mathrm{NaC} \mathrm{C}_{8}$ are respectively $\sim 300-$ $400 \mathrm{mM}$ and $\sim 1000-1200 \mathrm{mM}$ (ref. 26) while that for ${ }^{19} \mathrm{FIT}-27$ is $\sim 10 \mathrm{mM}$ (see also ESI Tables S1 and S2 $\uparrow$ for the detailed data before and after normalization). 
the successful use of ESI-MS to observe the formation of the surfactant aggregates. ${ }^{33}$

Positive mode ESI-MS spectra of ${ }^{19}$ FIT-27 were collected at various concentrations, from $0.38 \mathrm{mM}$ to $100 \mathrm{mM}$. Fig. 4 shows the spectrum at the highest concentration of ${ }^{19}$ FIT-27 $(100 \mathrm{mM})$. No concentration-dependent changes in ESI-MS spectra for ${ }^{19}$ FIT-27 were observed in the experimental concentration range (see ESI, Fig. S2 $\dagger$ ). Whereas very minor populations of dimeric ${ }^{19}$ FIT-27 were persistently observed and potential degradation products were occasionally observed, the various mass spectral peaks corresponding to the monomeric ${ }^{19}$ FIT-27 were overwhelmingly abundant (Fig. 4 and ESI, Fig. S2 $\dagger$ ). Furthermore, any putative concentration-dependent accumulation of either higher order oligomers or degradation products were largely absent. The absence of concentration-dependent behavior suggests that any presence of dimers and degradation products are largely artefactual (in-source dimerization and fragmentation) and the abundance of monomeric mass peaks confirms the previously determined ${ }^{12}$ monomeric nature of ${ }^{19}$ FIT-27 in solution.

Conformational transition of ${ }^{19}$ FIT-27 affects drift times in IM-MS. Since ESI-MS provided no evidence of ${ }^{19}$ FIT-27 micellization/assembly as its concentration increases from $0.38 \mathrm{mM}$ to $100 \mathrm{mM}$, we explored whether mass-spectrometry can provide evidence of a conformational transition. The conformational transition of ${ }^{19}$ FIT-27 results in a noticeable decrease in the molecular dimensions of the dendrimer with the maximum dimension $d_{\max }$, decreasing from $51 \AA$ to $47 \AA$, and the radius of gyration $R_{\mathrm{g}}$ decreasing from $17.8 \AA$ to $17.2 \AA^{12}$ The resulting molecular dimension changes could be reliably monitored by IM-MS. IM-MS probes the dimensions of molecules in the gas phase by measuring their transit time through a travelling wave ion mobility cell filled with an inert collision gas (here $\mathrm{N}_{2}$ ). Molecules with larger collisional cross-sections collide with gas molecules more frequently, and thus take longer time to travel through the tube. For biological molecules, such as proteins, it has been shown that aspect ratios of their solution structures can often be retained in the gas phase if ionization conditions are sufficiently gentle. For example, globular proteins have been found to retain their compactness, and multi-protein complexes have maintained their stoichiometry. ${ }^{34}$ To our knowledge, this ability to maintain solution conformation in the gas phase has not been demonstrated for synthetic polymers or dendrimers. Based on these observations and the $\sim 25 \%$ volume compaction of ${ }^{19}$ FIT-27 upon transition (from $\sim 3.5 \times 10^{4} \AA^{3}$ to $\sim 2.6 \times 10^{4} \AA^{3}$, calculated from SAXS data $^{12}$ ), we expect the compact form of ${ }^{19}$ FIT-27 to have shorter drift time than the extended one, due to the former having smaller size than the latter. To verify, we have monitored the concentration-dependent drift time of the positively charged ion $\left[{ }^{19}\right.$ FIT-27] $\mathrm{Na}^{+}(\mathrm{m} / \mathrm{z}$ 1930.6 Da, see Fig. 4).

Within the experimental concentration range of ${ }^{19}$ FIT-27, we detected subtle changes in the drift times of the single peak corresponding to the positively charged ion $\left[{ }^{19} \mathrm{FIT}-27\right] \mathrm{Na}^{+}$ (Fig. 5(A)). At lower concentrations, the peak can be adequately fitted to a single Gaussian curve with the center of the peak giving the drift time, which is $17.9 \mathrm{~ms}$. Meanwhile, as $C\left({ }^{19}\right.$ FIT27) increases, the observed peak (arrival time distribution) gradually broadens and can no longer be adequately fitted by a single Gaussian curve (Fig. 5(A)). Most telling, the center of the broadened peak moves to shorter drift time, consistent with more compact structure at high $C\left({ }^{19}\right.$ FIT-27).

Quantitatively, the broadened spectral peak could be reliably described by a two-Gaussian fit (Fig. 5(B)) with deconvolution into a slower drifting component $(17.9 \mathrm{~ms}$, the same as with lower $C\left({ }^{19}\right.$ FIT-27)), and an emerging faster drifting component

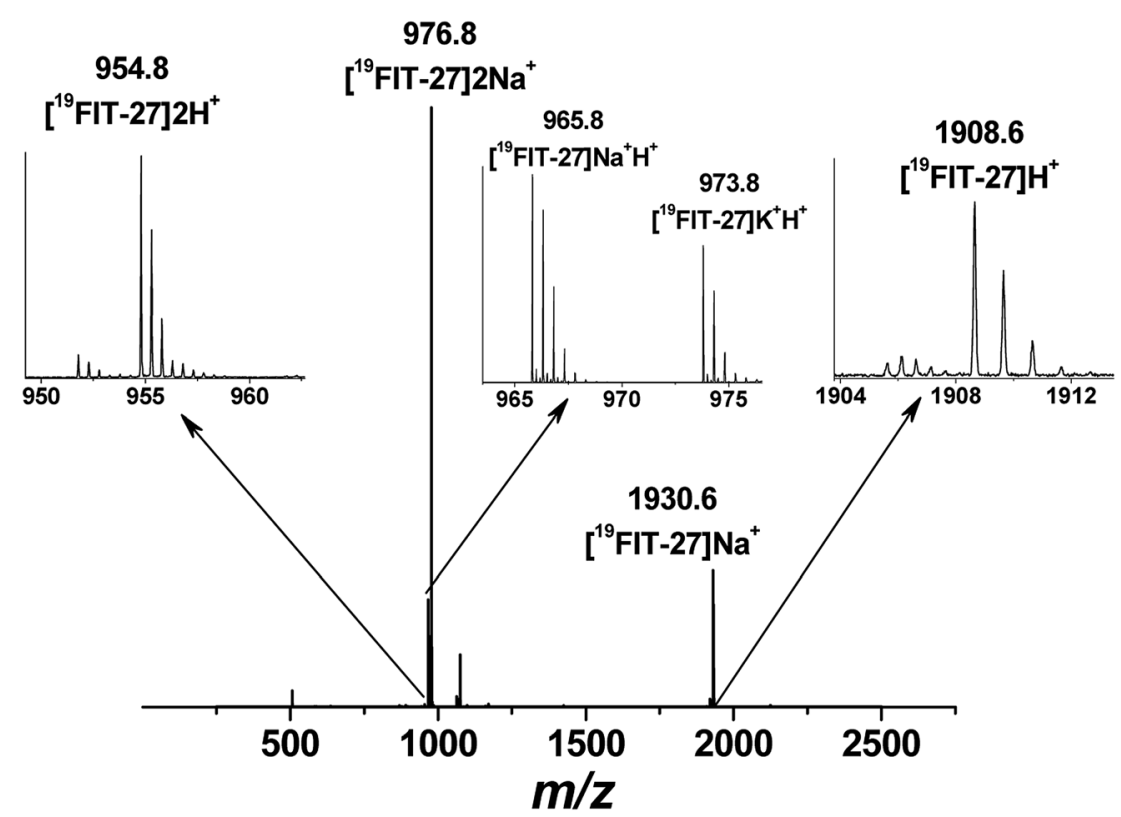

Fig. 4 Positive mode electrospray ionization mass-spectrum (ESI-MS) of ${ }^{19} \mathrm{FIT}-27$ at $100 \mathrm{mM}$ with peak assignment, showing no assemblies of the fluorinated dendrimer at highest concentration within the studied range. The molecular weight of monomeric ${ }^{19} \mathrm{FIT}-27$ is $1908 \mathrm{Da}$. 
(A)

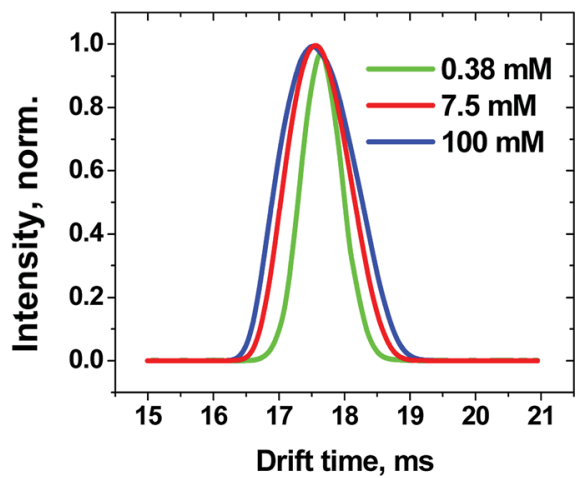

(C)

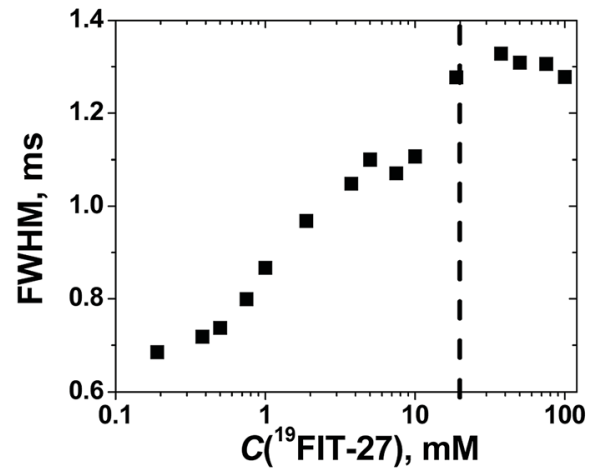

(B)

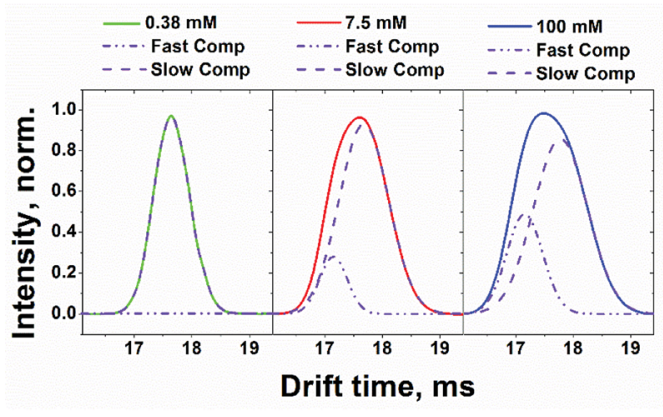

(D)

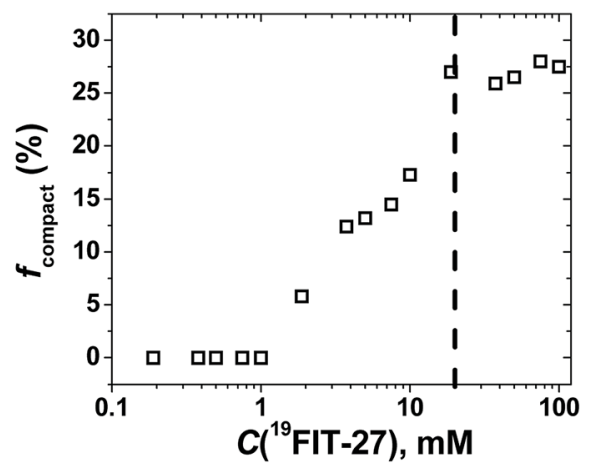

Fig. 5 Ion-mobility mass-spectrometry (IM-MS) characterization of ${ }^{19} \mathrm{FIT}-27$ at different concentrations. (A) Concentration-dependent changes in spectral peak width for $\left[{ }^{19} \mathrm{FIT}-27\right] \mathrm{Na}^{+}$; (B) single- and two-Gaussian deconvolution of the ion peaks shown in (A). The slow component has drift time of $17.9 \mathrm{~ms}$; the fast component, $17.2 \mathrm{~ms}$; (C) dependence of the full width at half-maximum (FWHM) of the ion peaks shown in (A) vs. C $\left({ }^{19} \mathrm{FIT}\right.$ 27); and (D) fraction of faster drifting compact form, $f_{\text {compact, }}$ of $\left[{ }^{19} \mathrm{FIT}-27\right] \mathrm{Na}^{+}$vs. C $\left({ }^{19} \mathrm{FIT}-27\right)$. The vertical dashed line in (C) and (D) highlights the transition point of $\sim 20 \mathrm{mM}$ in the gas phase.

(17.2 $\mathrm{ms}$ ). This result points to two dendrimer populations detected by IM-MS-one with a slower drift time of $17.9 \mathrm{~ms}$ corresponding to the extended form of the dendrimer, and another with a faster drift time of $\mathbf{1 7 . 2} \mathrm{ms}$ corresponding to the compact form of the dendrimer. At first glance, such small changes in drift time distribution (3.9\% reduction) may not seem to correlate well with the above mentioned significant volume reduction (25\%) upon transition. However, drift time in IM-MS is determined by collision cross-section, not volume. We, therefore, used previously generated ${ }^{12}$ low-resolution SAXS 3D models at $1 \mathrm{mM}$ and $10 \mathrm{mM}{ }^{19}$ FIT-27 to calculate collision crosssection by means of IMPACT projection approximation routine ${ }^{35}$ and determined that, upon transition, there is only $\sim 1.5 \%$ reduction in collision cross section $\left(\sim 1767.6 \AA^{2}\right.$ at $1 \mathrm{mM}$ vs. $\sim 1741.3 \AA^{2}$ at $\left.10 \mathrm{mM}\right)$. This explains the small decrease of drift time observed upon conformational transition.

The appearance of the faster drifting component broadens the IM-MS peak of the $\left[{ }^{19} \mathrm{FIT}-27\right] \mathrm{Na}^{+}$ion. The full width of the arrival time distribution at half-maximum (FWHM) demonstrates steady growth until the plateau, at which point no further changes were observed (Fig. 5(C)). Based on the twoGaussian fits of the drift peak at higher concentrations, one might estimate the fraction of the compact form ( $\left.f_{\text {compact }}\right)$ calculated from the areas of deconvoluted peaks. Fig. 5(D) shows the gradual growth of $f_{\text {compact }}$, which, similar to FWHM, also demonstrates plateauing at higher concentrations.

The plateau point in Fig. 5(C) and (D) give an estimate of the ${ }^{19}$ FIT-27 conformational transition point in the gas phase. As the data shows, the conformational transition point is delayed from $\sim 10 \mathrm{mM}$ in aqueous solution to $\sim 20 \mathrm{mM}$ in the gas phase. Also, similar to the pre-transition gradual changes of $\delta\left({ }^{19} \mathrm{~F}\right)$ (Fig. 2(D)), both FWHM and $f_{\text {compact }}$ display gradual pretransition changes (Fig. 5(C) and (D)). Such pre-transition changes demonstrate the sensitivity of IM-MS towards the increasing presence of the compact form of ${ }^{19}$ FIT-27 similar to ${ }^{19}$ F NMR above.

The conformational transition of ${ }^{19}$ FIT-27 is not only delayed to a higher concentration, but also incomplete; $f_{\text {compact }}$ is less than $30 \%$ completely transitioned even at $100 \mathrm{mM}$. From our previous SAXS and SANS experiments in aqueous solutions, ${ }^{12}$ one might conclude that at $100 \mathrm{mM}$ the transition of ${ }^{19}$ FIT-27 into its compact form should be almost complete. Such discrepancies between liquid and gas state results are consistent with the weakened driving force for folding. The unavoidable partial dehydration in the vacuum chamber of the MS instrument could lead to a shift in the equilibrium and/or kinetics of interconversion between the extended and compact forms. The observed delay and incomplete 
conformational transition of ${ }^{19}$ FIT-27 in the gas phase supports the proposition that the transition is driven, at least in part, by the need to shield the ${ }^{19} \mathrm{~F}_{3} \mathrm{C}$-groups from water.

In sum, no supramolecular assemblies of ${ }^{19}$ FIT-27 were detected by mass-spectrometry within the concentration range from $0.38 \mathrm{mM}$ to $100 \mathrm{mM}$. IM-MS found evidence of the conformational transition of ${ }^{19}$ FIT-27 at higher concentrations. These observations confirm that shielding of fluorocarbon groups from water is part of the driving force of the conformational transition of ${ }^{19}$ FIT-27.

\section{Conclusions}

This work and its predecessor ${ }^{12}$ provide evidence of an asymmetric dendritic amphiphile, ${ }^{19}$ FIT-27, that undergoes conformational transition rather than micellization when its concentration exceeds certain level. This conclusion is supported by direct characterization of ${ }^{19}$ FIT-27 (SAXS, SANS, DLS, ${ }^{19} \mathrm{~F}$ NMR and MS), indirect characterization of ${ }^{19}$ FIT-27 $\left({ }^{1} \mathrm{H}_{2} \mathrm{O}\right.$ NMR), and side-by-side comparison of ${ }^{19}$ FIT-27 with both micelle-forming $\left(\mathrm{NaFC}_{8}, \mathrm{NaC}_{8}\right)$ and non-micelle-forming $(\alpha-\mathrm{CD})$ amphiphiles. The origin of conformational transition in lieu of micellization likely lies in the shape of the amphiphile, which is incompatible with micellization. This points to a potential strategy to design novel amphiphiles with unconventional properties.

\section{Experimental section}

\section{Materials}

Synthesis of the fluorinated amphiphilic dendrimer, ${ }^{19}$ FIT-27, followed the earlier described procedure, ${ }^{9}$ modified in order to introduce an additional methylene group $\left(-\mathrm{CH}_{2}-\right)$ separating the hydrophobic fluorocarbon head and the hydrophilic tetraoxyethylene tails (Fig. 1). ${ }^{\mathbf{1 2}}$ Sodium perfluorooctanoate $\left(\mathrm{NaFC}_{8}\right.$, Sigma-Aldrich), sodium octanoate $\left(\mathrm{NaC}_{8}\right.$, SigmaAldrich), and $\alpha$-cyclodextrin ( $\alpha$-CD, TCI-GR) were used without further purification.

\section{Sample preparation}

${ }^{19}$ FIT-27. For NMR experiments, stock solution of $100 \mathrm{mM}$ ${ }^{19}$ FIT-27 was prepared in PBS buffer (50 mM sodium phosphate, $100 \mathrm{mM}$ NaCl, pH 7.4 in ${ }^{1} \mathrm{H}_{2} \mathrm{O}$ ). The same PBS buffer was used in serial volumetric dilutions of the above stock solution to obtain the samples within the concentration range from $0.2 \mathrm{mM}$ to $100 \mathrm{mM}$ (17 samples; 0.19, 0.22, 0.28, 0.38, 0.5, 0.75, 1.0, 1.88, $3.75,5.0,7.5,10.0,18.8,37.5,50.0,75.0,100.0 \mathrm{mM})$. Same procedure was followed when preparing ${ }^{19}$ FIT-27 samples for ESI-MS and IM-MS experiments, however, LC/MS grade water was used as a solvent instead of PBS buffer.

Sodium perfluorooctanoate $\left(\mathrm{NaFC}_{\mathbf{8}}\right)$. Stock solution of $500 \mathrm{mM} \mathrm{NaFC}{ }_{8}$ was prepared in ultrapure water (18.2 MOhm). This solution was used to prepare 16 samples of different concentration of $\mathrm{NaFC}_{8}(1.7,2.5,3.9,5.8,8.7,13.0,19.5,29.3$, $36.6,43.9,65.8,98.8,148.2,222.2,333.3$, and $500 \mathrm{mM}$ ) by serial volumetric dilutions with the same ultrapure water. For complete dissolution, all solutions were slowly nutated overnight at room temperature.

Sodium octanoate $\left(\mathrm{NaC}_{8}\right)$. Stock solution of $2.40 \mathrm{M}$ of $\mathrm{NaC}_{8}$ was prepared in ultrapure water (18.2 MOhm). This solution was used to prepare 15 samples of different concentrations of $\mathrm{NaC}_{8}$ (0.009, 0.014, 0.019, 0.038, 0.075, 0.15, 0.30, 0.60, 0.90, $1.20,1.50,1.80,2.00,2.20$, and $2.40 \mathrm{M}$ ) were prepared using volumetric serial dilution with the same ultrapure water. For complete dissolution, all solutions were slowly nutated overnight at room temperature.

$\alpha$-Cyclodextrin ( $\alpha$-CD). Stock solution of $105.0 \mathrm{mM}$ of $\alpha$-CD was prepared in ultrapure water (18.2 MOhm). This solution was used to prepare 15 samples of different concentrations of $\alpha$ CD $(0.2,0.5,1.0,2.1,3.3,4.6,6.0,7.5,9.5,13.0,20.0,30.0,40.0$, 60.0 , and $105.0 \mathrm{mM}$ ) were prepared using volumetric serial dilution with the same ultrapure water.

\section{NMR experiments}

All ${ }^{1} \mathrm{H}$ and ${ }^{19} \mathrm{~F}$ NMR experiments were carried out using a Varian INOVA 400 NMR spectrometer (Varian, Inc., $399.75 \mathrm{MHz}$ for ${ }^{1} \mathrm{H}$ and $376.11 \mathrm{MHz}$ for ${ }^{19} \mathrm{~F}$ ) using a broadband detection probe. In all NMR experiments the temperature of sample solutions always was $22{ }^{\circ} \mathrm{C}\left( \pm 0.1{ }^{\circ} \mathrm{C}\right)$.

Measurements of chemical shift $\delta\left({ }^{19} \mathbf{F}\right)$. Two hundred $\mu \mathrm{L}$ of each ${ }^{19}$ FIT-27 or $\mathrm{NaFC}_{8}$ solution at different concentrations were aliquoted into a standard $3 \mathrm{~mm}$ NMR tube (Norell, Inc.), which was then inserted into a standard outer $5 \mathrm{~mm}$ NMR tube. In all ${ }^{19} \mathrm{~F}$ NMR experiments, this outer $5 \mathrm{~mm}$ tube was filled with $\mathrm{D}_{2} \mathrm{O}$ (deuterium lock) that contained $\sim 5 \mathrm{mM}$ trifluoroacetic acid (TFA) as the ${ }^{19} \mathrm{~F}$ chemical shift external reference $\left(\delta_{\mathrm{TFA}}\left({ }^{19} \mathrm{~F}\right)=\right.$ $-76.55 \mathrm{ppm}) .{ }^{25}$ Fluorine chemical shift $\delta\left({ }^{19} \mathrm{~F}\right)$ data of were collected by means of standard single pulse sequence with 64 accumulated transients at various concentrations of ${ }^{19}$ FIT-27 and $\mathrm{NaFC}_{8}$.

Measurements of water proton transverse relaxation rate $\boldsymbol{R}_{\mathbf{2}}\left({ }^{1} \mathbf{H}_{2} \mathbf{O}\right)$. Two hundred $\mu \mathrm{L}$ of each ${ }^{19}$ FIT-27, $\mathrm{NaC}_{8}$, or $\alpha$-CD solution at different concentrations were aliquoted into a standard $3 \mathrm{~mm}$ NMR tube (Norell, Inc.), which was then inserted into a standard outer $5 \mathrm{~mm}$ NMR tube. The external deuterium lock and reference standard solvent in this outer $5 \mathrm{~mm}$ NMR tube was deuterated cyclohexane- $d_{12}$ (Sigma-Aldrich; residual protons $\delta\left({ }^{1} \mathrm{H}\right)=1.38 \mathrm{ppm}$ (ref. 36$)$ ). The transverse relaxation rate of water $R_{2}\left({ }^{1} \mathrm{H}_{2} \mathrm{O}\right)$ in solutions of ${ }^{19}$ FIT-27, $\mathrm{NaC}_{8}$, and $\alpha$-CD were measured using the conventional CPMG (Carr-PurcellMeiboom-Gill) pulse sequence. ${ }^{37}$ The transverse relaxation time $T_{2}\left(=1 / R_{2}\right)$ can be extracted from experimental data via the following equation:

$$
I(t)=I_{0} \times \exp \left(-t / T_{2}\right)
$$

where $I(t)$ is the signal intensity of ${ }^{1} \mathrm{H}_{2} \mathrm{O}$ protons at time $t ; I_{0}$ is the initial signal intensity at $t=0$; and $t$ is the $T_{2}$ delay time. In this experiments the interpulse delay between $180^{\circ}$-pulses was $120 \mu \mathrm{s}$, and 4 transients were collected. In order to avoid radiation damping effects of water, a small flip-angle $\left(\sim 9-10^{\circ}\right)$ excitation pulse was used instead of the usual $90^{\circ}$ flip-angle in the CPMG pulse sequence. NMR data were processed using 
SpinWorks 4.1 software (University of Manitoba, Canada) and plotted and fitted using Origin 8.1 (OriginLab Corp.).

\section{Mass spectrometry experiments}

All mass spectrometry data were acquired on a Waters Synapt G2 (Waters Co.) in electrospray ionization (ESI-MS) mode with direct infusion. All data acquisitions were performed in positive resolution mode at $3 \mathrm{kV}$ capillary voltage, $30 \mathrm{~V}$ sample cone voltage, $5 \mathrm{~V}$ extraction cone voltage, $80{ }^{\circ} \mathrm{C}$ cone temperature, $175{ }^{\circ} \mathrm{C}$ desolvation temperature and $10 \mathrm{eV}$ transfer collision energy. Data acquired were integrated over acquisition time in Masslynx software and exported for further analysis.

Ion mobility-mass spectrometry (IM-MS). Solutions of ${ }^{19}$ FIT27 at various concentrations in LC/MS grade $\mathrm{H}_{2} \mathrm{O}$ were directly infused, and drift time was monitored and acquired for a minimum of 2 minutes under the mobility time-of-flight acquisition mode. In the traveling wave ion mobility cell, a traveling wave speed of $650 \mathrm{~m} \mathrm{~s}^{-1}$ and height of $40 \mathrm{~V}$ was applied. The drift time distribution of the $\left[{ }^{19}\right.$ FIT-27] $\mathrm{Na}^{+}$cluster $(\mathrm{m} / \mathrm{z}=1930.6)$ was fitted to Gaussian distributions in Origin 8.1 (OriginLab Corp.). The analyses were based on the extracted values of full widths at half-maximum (FWHM) and corresponding areas of fitted peaks for relative contributions of the extended and compact forms of ${ }^{19}$ FIT-27.

\section{Conflicts of interest}

There are no conflicts of interest to declare.

\section{Acknowledgements}

Early phase of this work was supported by an NSF grant (CBET 1133908). Mass-spectrometry experiments were supported in part by the University of Maryland Baltimore, School of Pharmacy Mass Spectrometry Center (SOP1841-IQB2014). Financial support from the University of Maryland, Baltimore and the University of Maryland, College Park seed grant is gratefully acknowledged.

\section{References}

1 N. Muller and R. H. Burkhahn, J. Phys. Chem., 1967, 71, 957962.

2 T. Loftsson and M. E. Brewster, J. Pharm. Sci., 1996, 85, 10171025.

3 P. Jansook, N. Ogawa and T. Loftsson, Int. J. Pharm., 2018, 535, 272-284.

4 (a) A. J. M. Valente, R. A. Carvalho and O. Södermann, Langmuir, 2015, 31, 6314-6320; (b) A. J. M. Valente, R. A. Carvalho, D. Martinho and O. Södermann, Langmuir, 2017, 33, 8233-8238.

5 A. Ryzhakov, T. Do Thi, J. Stappaerts, L. Bertoletti, K. Kimpe, A. R. Sá Kouto, P. Saokham, G. Van den Mooter, P. Augustijns, G. W. Somsen, S. Kurkov, S. Inghelbrecht, A. Arien, M. I. Jimidar, K. Schrijnemakers and T. Loftsson, J. Pharm. Sci., 2016, 105, 2556-2569.
6 F. Salas and R. Darcy, Eur. J. Org. Chem., 2008, 957-969.

7 Z.-X. Jiang and Y. B. Yu, J. Org. Chem., 2010, 75, 2044-2049.

8 X. Yue, M. B. Taraban, L. L. Hyland and Y. B. Yu, J. Org. Chem., 2012, 77, 8879-8887.

9 Z.-X. Jiang, X. Liu, E. K. Jeong and Y. B. Yu, Angew. Chem., Int. Ed., 2009, 48, 4755-4758.

10 K. L. Meyer, M. J. Carvlin, B. Mukherji, H. A. Sloviter and P. M. Joseph, Invest. Radiol., 1992, 27, 620-627.

11 Y. Nosé, Artif. Organs, 2004, 28, 807-812.

12 M. B. Taraban, Y. Li, Y. Feng, E. V. Jouravleva, M. A. Anisimov, Z.-X. Jiang and Y. B. Yu, $R S C A d v .$, 2014, 4, 54565-54575.

13 N. Muller and H. Simsohn, J. Phys. Chem., 1971, 75, 942-945. 14 L. Nordstierna, P. V. Yushmanov and I. Furó, J. Phys. Chem. $B, 2006,110,25775-25781$.

15 (a) A. Richter, A. Wiedekind, M. Krause, T. Kissel, R. Haag and C. Olbrich, Eur. J. Pharm. Sci., 2010, 40, 48-55; (b) R. Tyagi, S. Malhotra, A. F. Thünemann, A. Sedighi, M. Weber, A. Schäfer and R. Haag, J. Phys. Chem. C, 2013, 117, 12307-12317; (c) D. R. Sikwal, R. S. Kalhapure, M. Jadhav, S. Rambharose, C. Mocktar and T. Govender, RSC Adv., 2017, 7, 14233-14246.

16 Y. Feng, M. B. Taraban and Y. B. Yu, Chem. Commun., 2015, 51, 6804-6807.

17 (a) B. T. Ruotolo, J. L. Benesch, A. M. Sandercock, S.-J. Hyung and C. V. Robinson, Nat. Protoc., 2008, 3, 1139-1152; (b) Y. Zhong, S.-J. Hyung and B. T. Ruotolo, Expert Rev. Proteomics, 2012, 9, 47-58.

18 M. B. Taraban, Y. Feng, B. Hammouda, L. L. Hyland and Y. B. Yu, Chem. Mater., 2012, 24, 2299-2310.

19 S. J. Law and M. M. Britton, Langmuir, 2012, 28, 1169911706.

20 J. Ulmius and B. Lindman, J. Phys. Chem., 1981, 85, 41314135.

21 K. Shinoda, M. Hato and T. Hayashi, J. Phys. Chem., 1972, 76, 909-914.

22 S. S. Berr and R. R. M. Jones, J. Phys. Chem., 1989, 93, 25552558.

23 H. Gustavsson and B. Lindman, J. Am. Chem. Soc., 1978, 100, 4647-4654.

24 (a) W. Al-Soufi, L. Piñeiro and M. Novo, J. Colloid Interface Sci., 2012, 370, 102-110; (b) M. V. C. Cardoso and E. Sabadini, Langmuir, 2013, 29, 15778-157786.

25 J. Sloop, Rep. Org. Chem., 2013, 3, 1-12.

26 (a) J. B. Hayter and T. Zemb, Chem. Phys. Lett., 1982, 93, 9194; (b) B. O. Persson, T. Drakenberg and B. Lindman, J. Phys. Chem., 1979, 83, 3011-3015; (c) T. Zemb, M. Drifford, M. Hayoun and A. Jehanno, J. Phys. Chem., 1983, 87, 45244528; (d) D. K. Chokappa and S. Das, Indian J. Chem., 1994, 33A, 795-800.

27 W. Sliwa and T. Girek, Cyclodextrins: Properties and Applications, Wiley-VCH, Weinheim, 2017.

28 E. Sabadini, F. d. C. Egidio, F. Y. Fujiwara and T. Cosgrove, J. Phys. Chem. B, 2008, 112, 3328-3332.

29 P. Ekwall, in Chemistry, Physics and Application of Surface Active Substances, ed. J. Th. G. Overbeek, Gordon and Breach, New York, 1967, vol. 2, pp. 651-658. 
30 P. Ekwall and L. Mandell, J. Colloid Interface Sci., 1979, 69, 384-397.

31 (a) C. A. Scarff, A. E. Ashcroft and S. E. Redford, Methods Mol. Biol., 2016, 1345, 115-132; (b) G. Wang, A. J. Johnson and I. A. Kaltashov, Anal. Chem., 2012, 84, 1718-1724.

32 C. Bleiholder, N. F. Dupuis, T. Wyttenbach and M. T. Bowers, Nat. Chem., 2011, 3, 172-177.

33 L. Ceraulo, G. Giorgi, V. T. Liveri, D. Bongiorno, S. Indelicato, F. D. Gaudio and S. Indelicato, Eur. J. Mass Spectrom., 2011, 17, 525-541.
34 W. Hoffmann, G. von Helden and K. Pagel, Curr. Opin. Struct. Biol., 2017, 46, 7-15.

35 E. G. Marklund, M. T. Degiacomi, C. V. Robinson, A. J. Baldwin and J. L. P. Benesch, Structure, 2015, 23, 791799.

36 M. J. O'Nell, P. E. Heckelman, C. B. Kock and K. J. Roman, The Merck Index, an Encyclopedia of Chemicals, Drugs, and Biologics, Merck, Whitehouse Station, 2006.

37 (a) H. Y. Carr and E. M. Purcell, Phys. Rev., 1954, 94, 630-638; (b) S. Meiboom and D. Gill, Rev. Sci. Instrum., 1958, 29, 688691. 